\title{
Supplementary Material: Sensitivity of aerosol optical properties to the aerosol size distribution over central Europe and the Mediterranean Basin
}

Laura Palacios-Peña ${ }^{1}$, Jerome D. Fast ${ }^{2}$, Enrique Pravia-Sarabia ${ }^{1}$, and Pedro Jiménez-Guerrero ${ }^{1}$

${ }^{1}$ Physics of the Earth, Regional Campus of International Excellence "Campus Mare Nostrum", University of Murcia, Spain. ${ }^{2}$ Pacific Northwest National Laboratory, Richland, WA, USA

Correspondence: Pedro Jiménez-Guerreo (pedro.jimenezguerrero@um.es) 


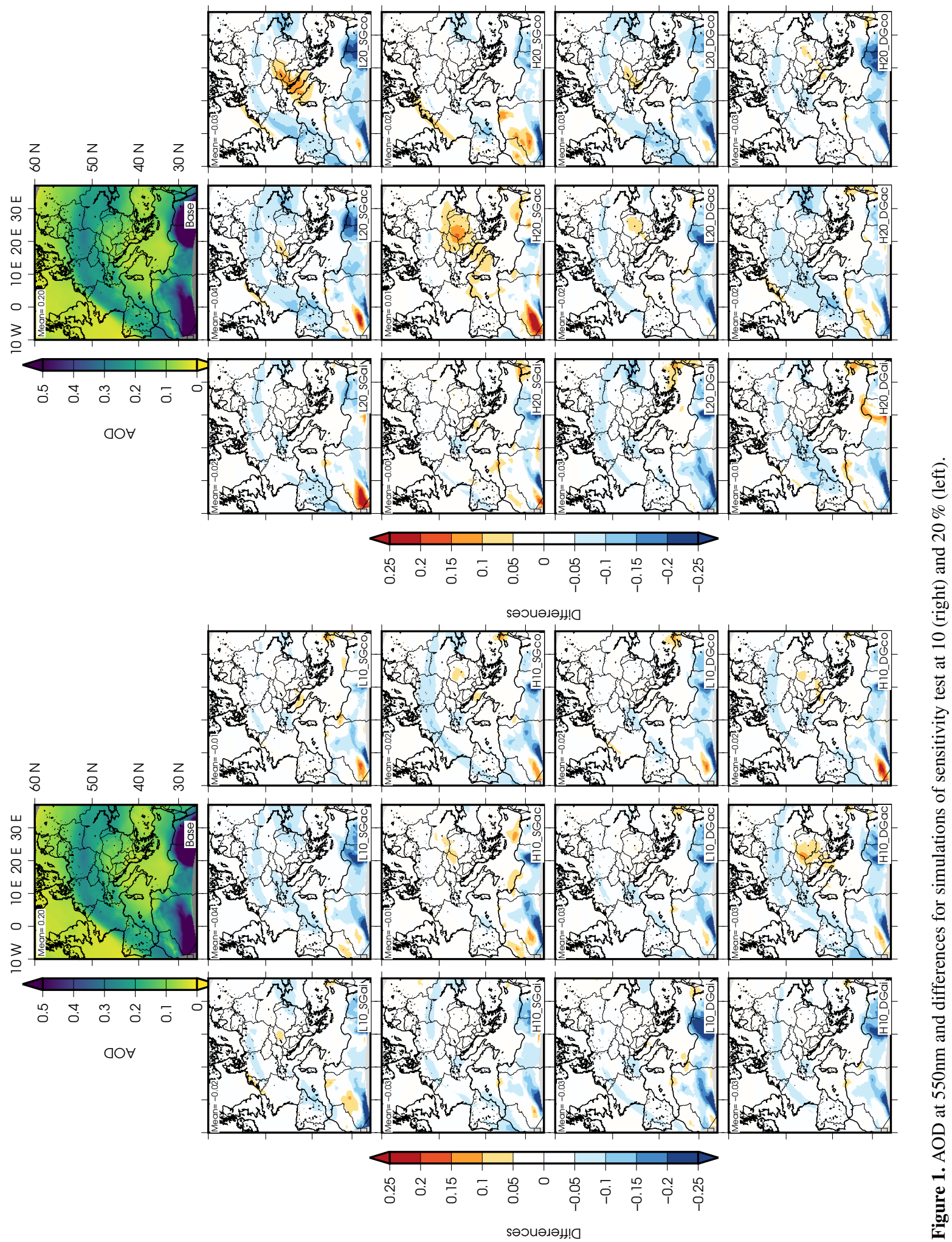



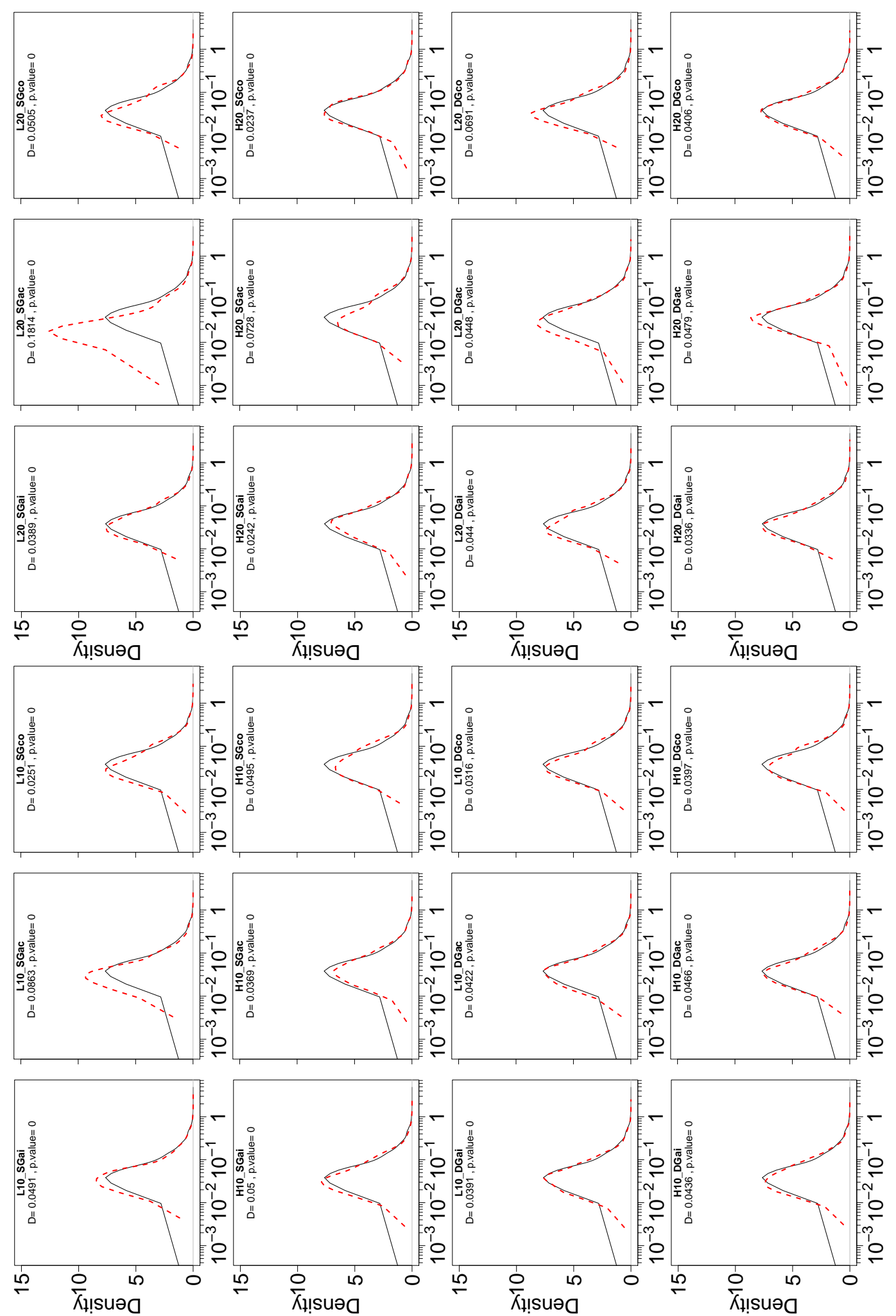

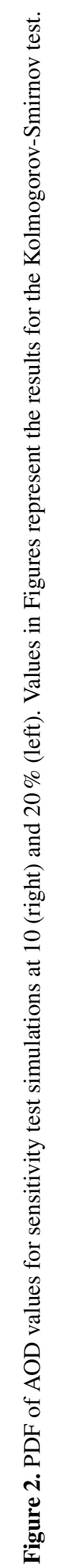




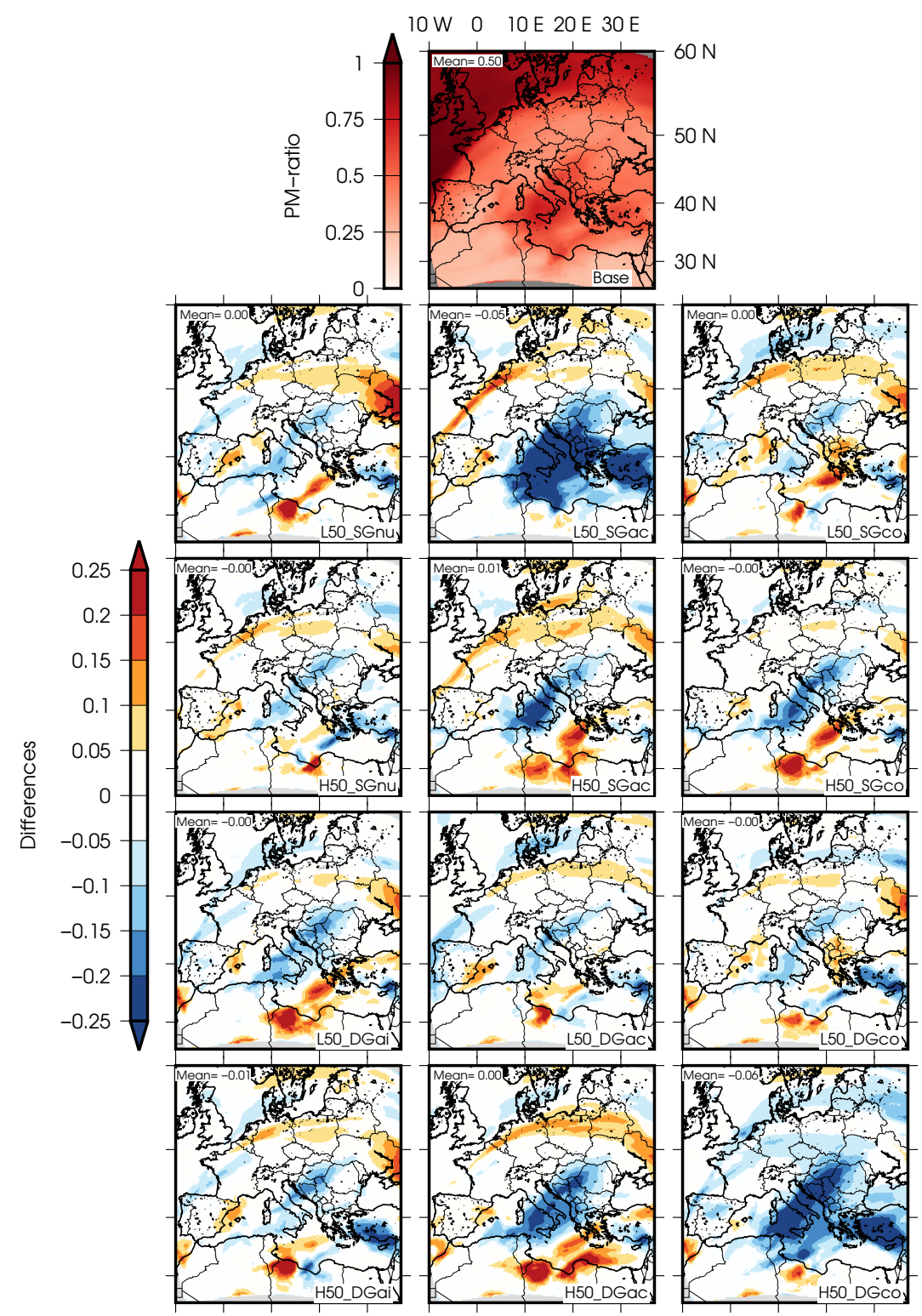

Figure 3. PM-ratio at $750 \mathrm{hPa}$ for the base case and differences for sensitivity test simulations at $50 \%$. 

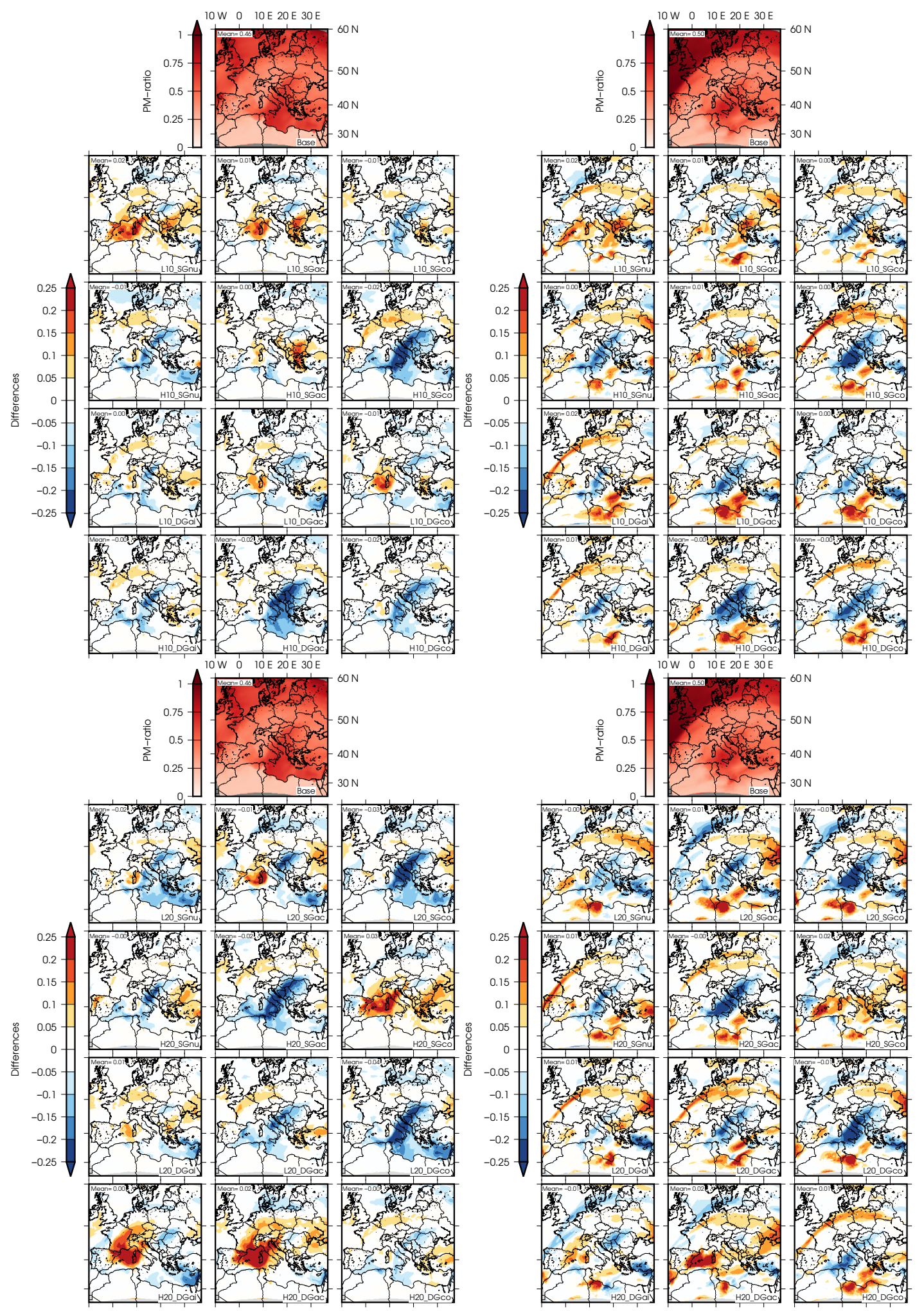

Figure 4. PM-ratio for sensitivity test at 10 (top) and $20 \%$ (bottom). Left at 1000 and right at $750 \mathrm{hPa}$. 


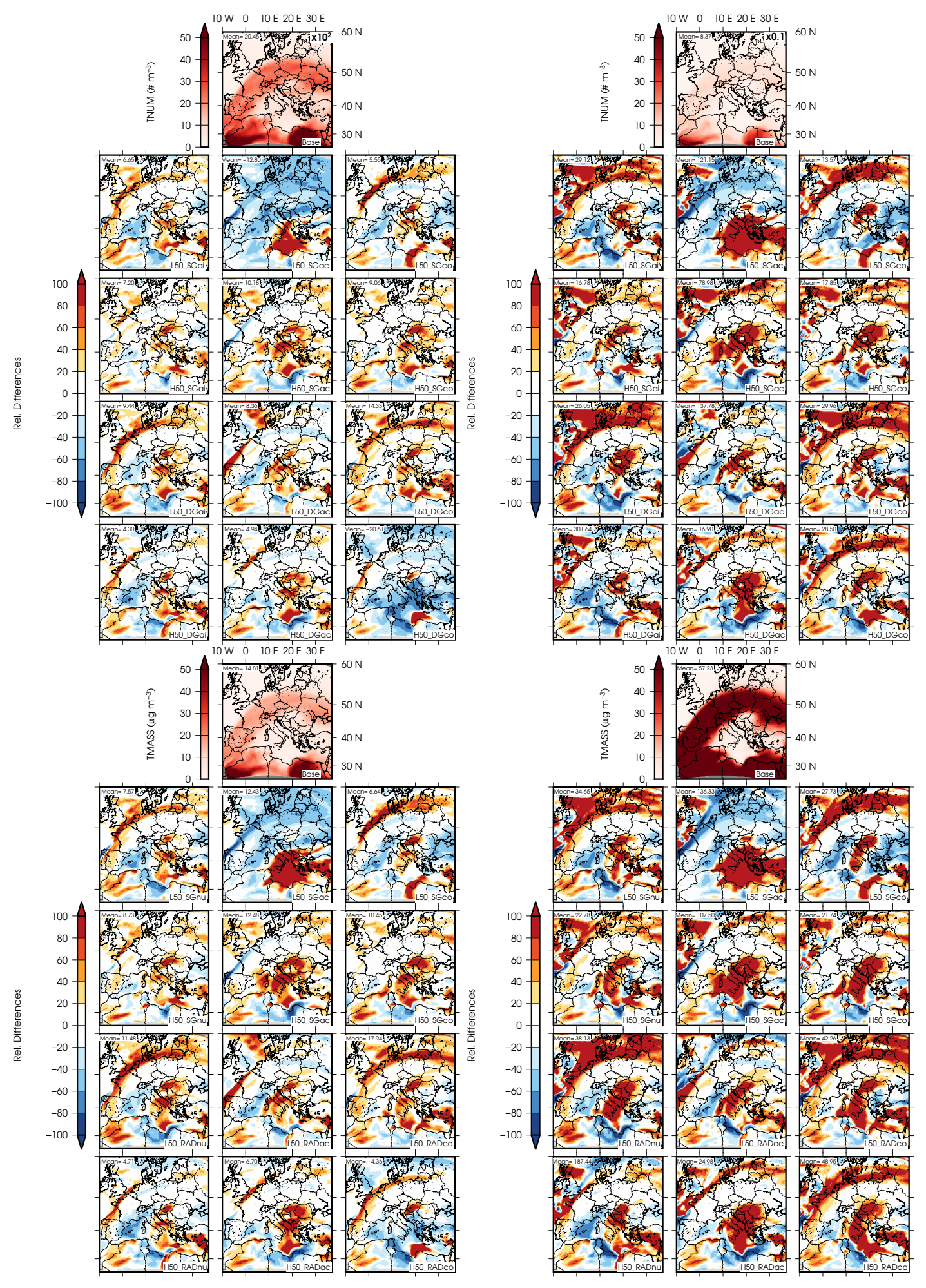

Figure 5. Total number concentration of particles (top) and total mass concentration (bottom) at $750 \mathrm{hPa}$ in the Aitken and accumulation (left) and coarse (right) modes for the base case and relative differences for sensitivity test simulations at $50 \%$. 

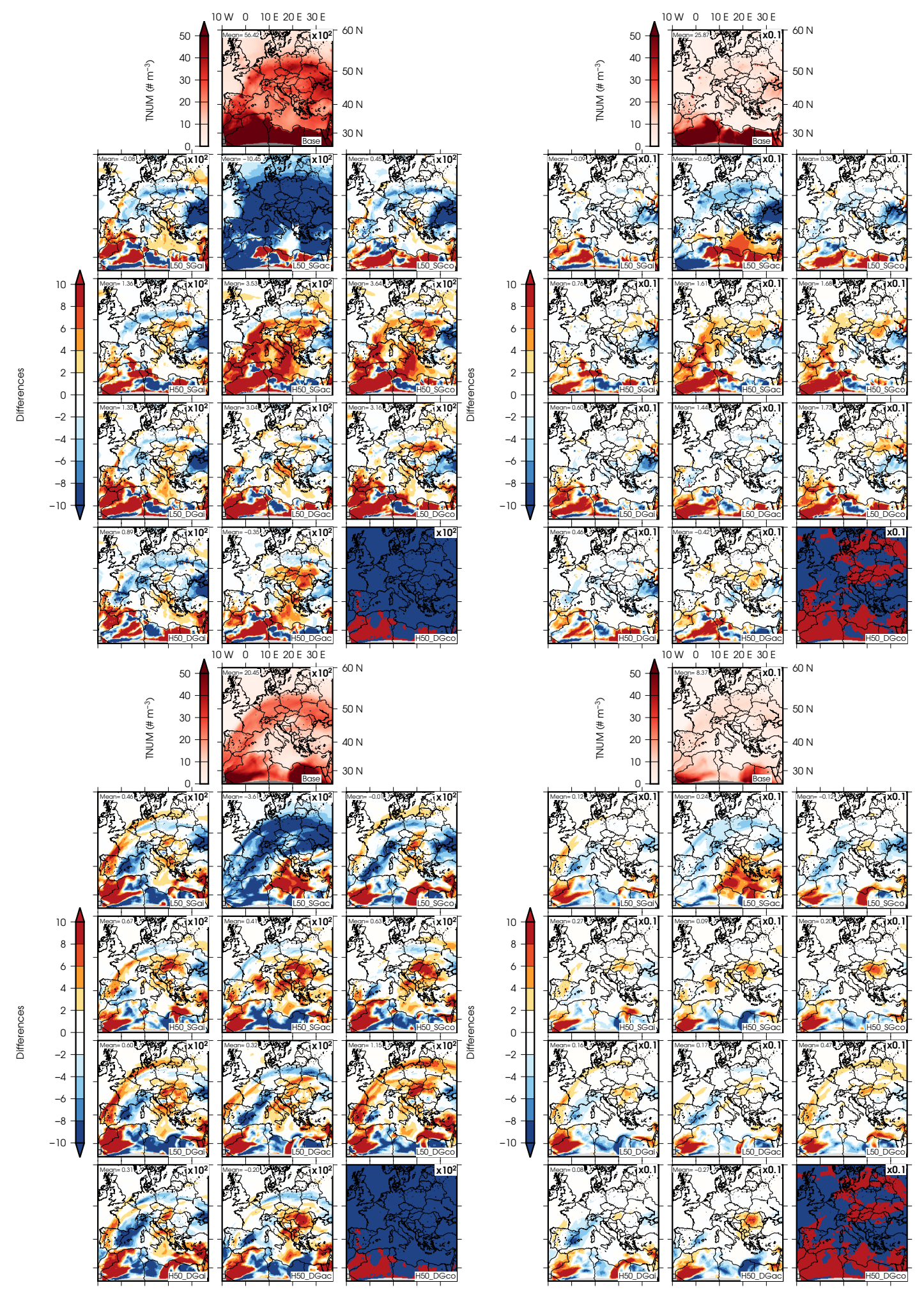

Figure 6. Total number concentration for Aitken and accumulation (right) and coarse (left) modes at 1000 (top) and $750 \mathrm{hPa}$ (bottom) and non-relative differences for the sensitivity test at $50 \%$. 


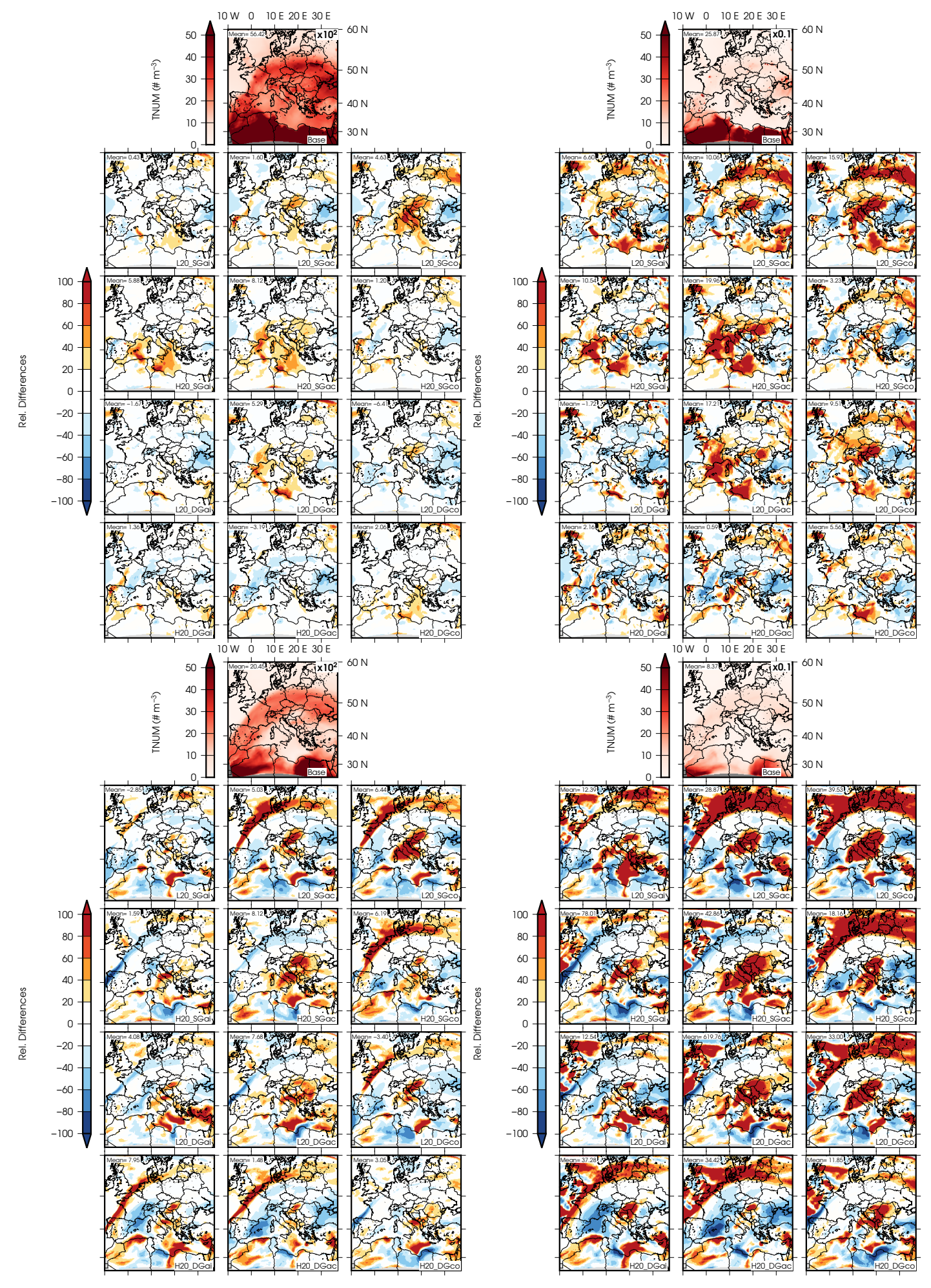

Figure 7. Total number concentration for Aitken and accumulation (right) and coarse (left) modes at 1000 (top) and $750 \mathrm{hPa}$ (bottom) and relative differences for the sensitivity test at $20 \%$. 

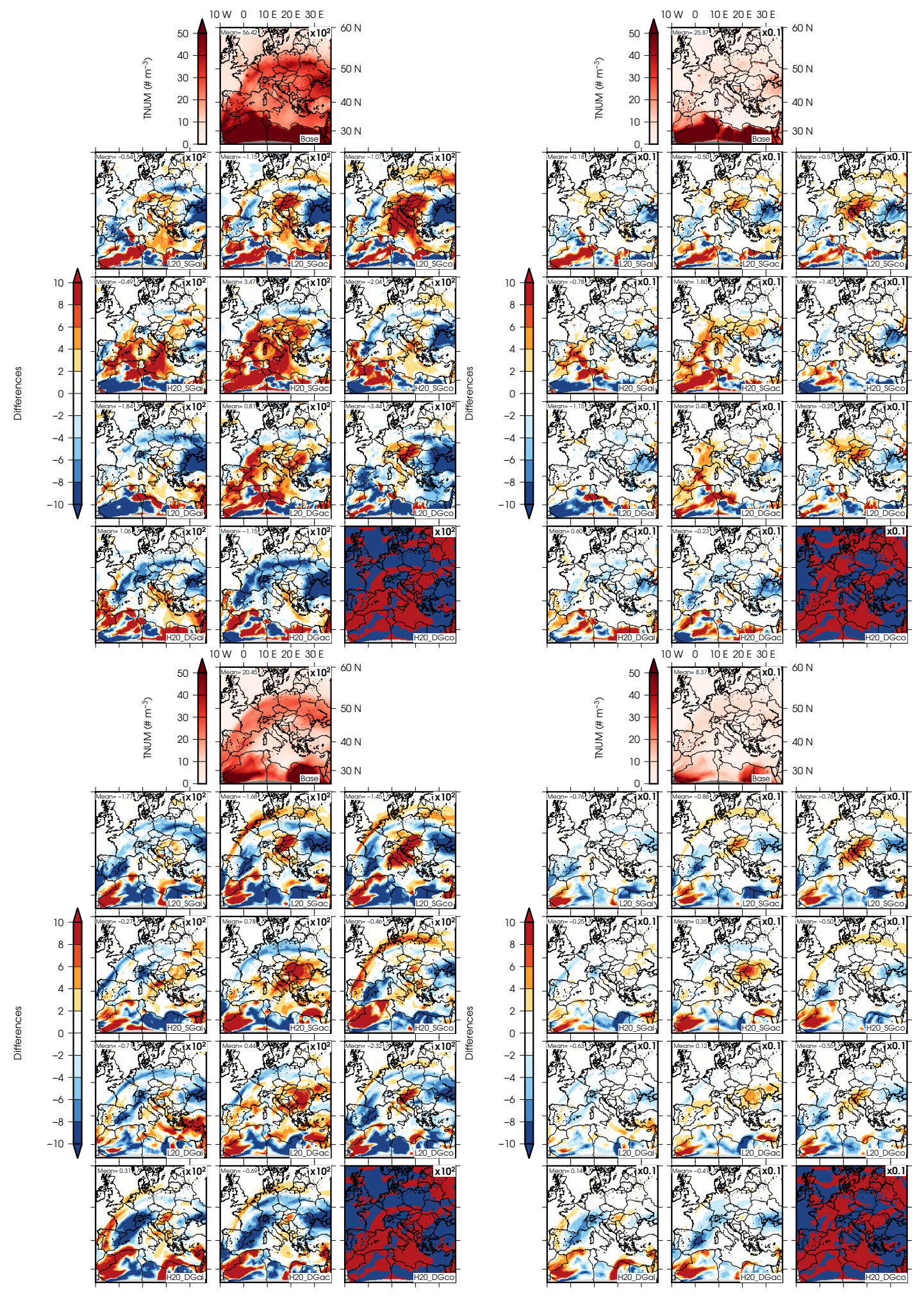

Figure 8. Id. Figure 6 but for sensitivity test at $20 \%$. 

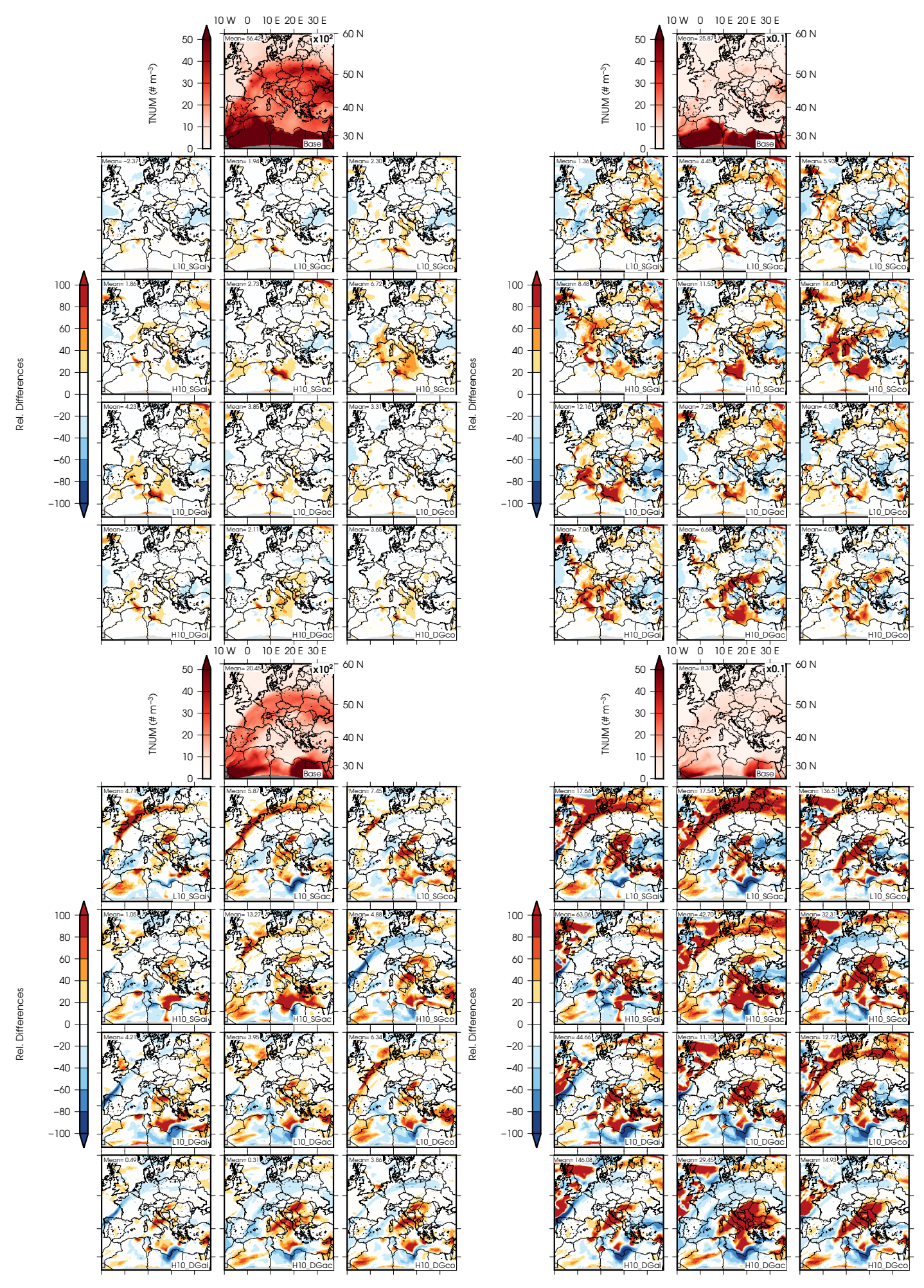

Figure 9. Id. Figure 7 but for sensitivity test at $10 \%$. 

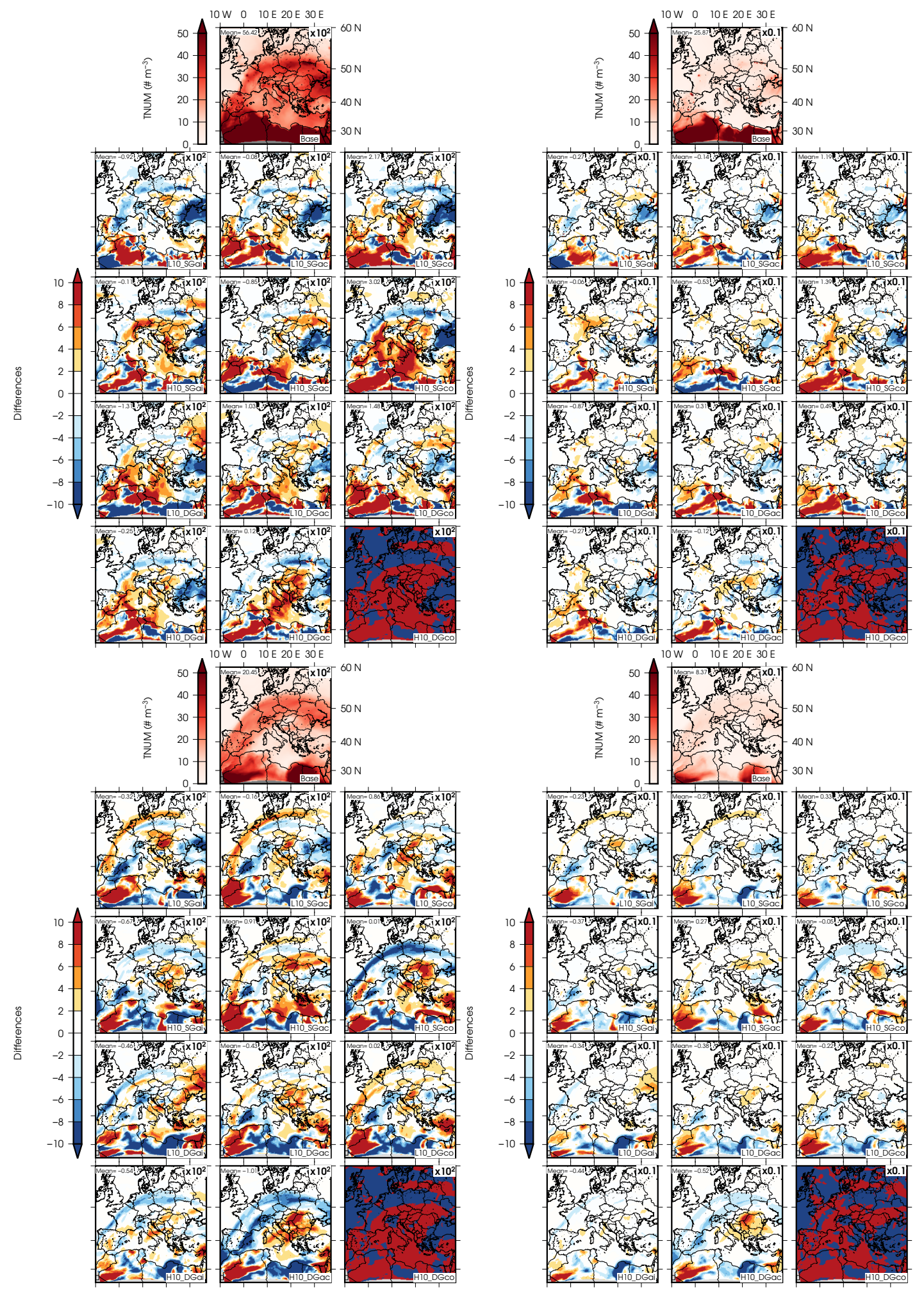

Figure 10. Id. Figure 6 but for sensitivity test at $10 \%$. 

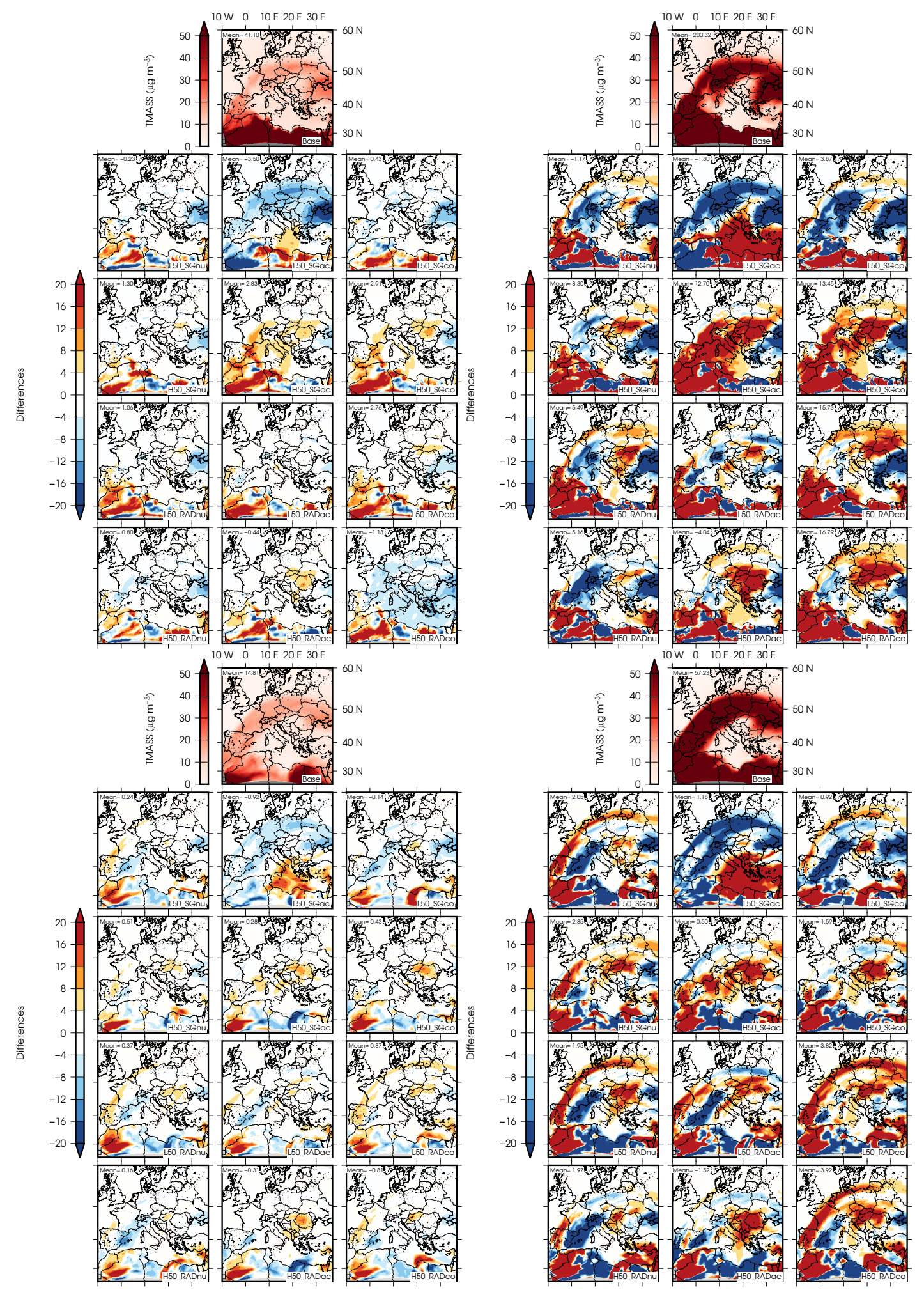

Figure 11. Total mass concentration for Aitken and accumulation (right) and coarse (left) modes at 1000 (top) and $750 \mathrm{hPa}$ (bottom) and non-relative differences for the sensitivity test at $50 \%$. 


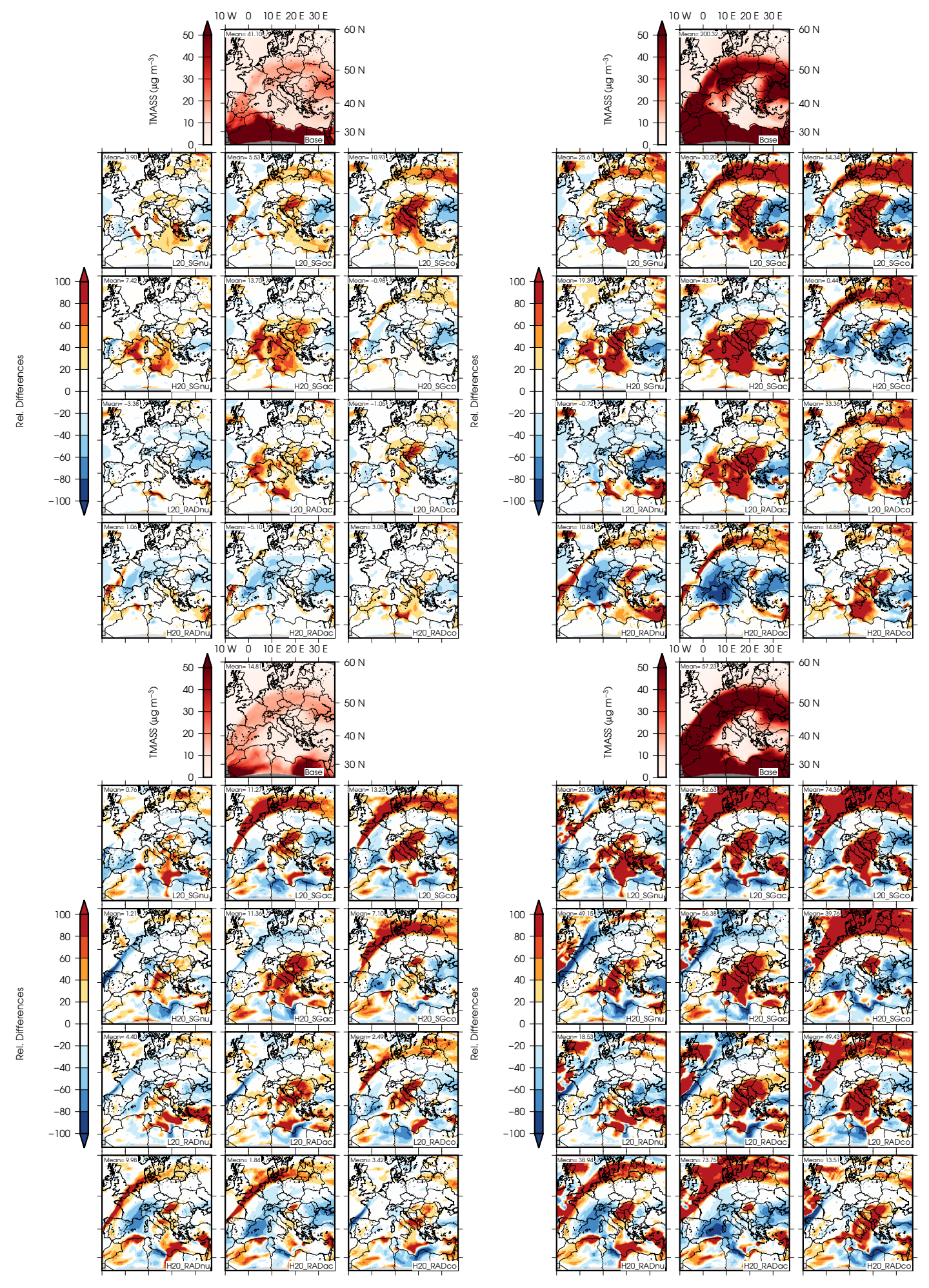

Figure 12. Total mass concentration for Aitken and accumulation (right) and coarse (left) modes at 1000 (top) and $750 \mathrm{hPa}$ (bottom) and relative differences for the sensitivity test at $20 \%$. 

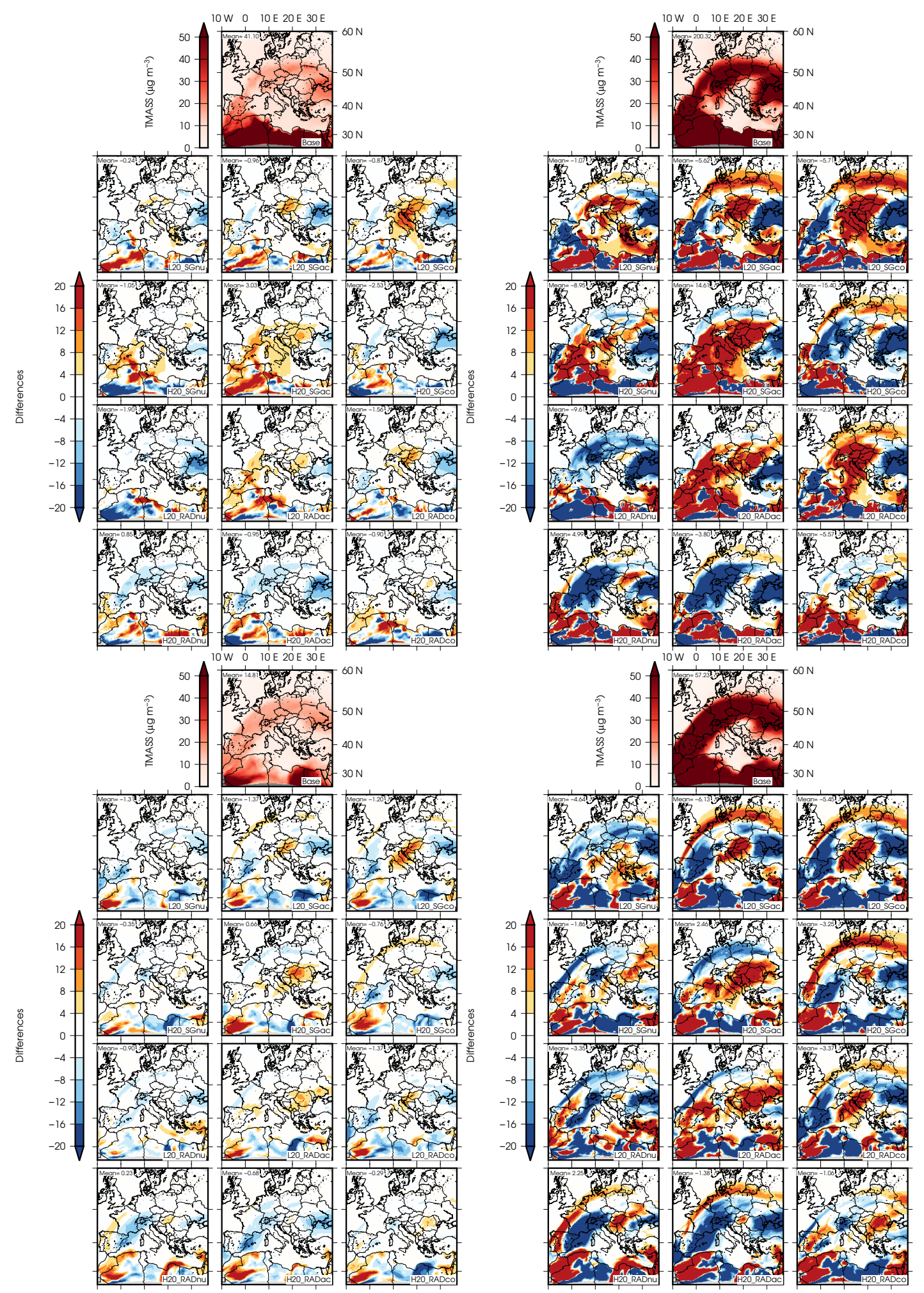

Figure 13. Id. Figure 11 but for sensitivity test at $20 \%$. 

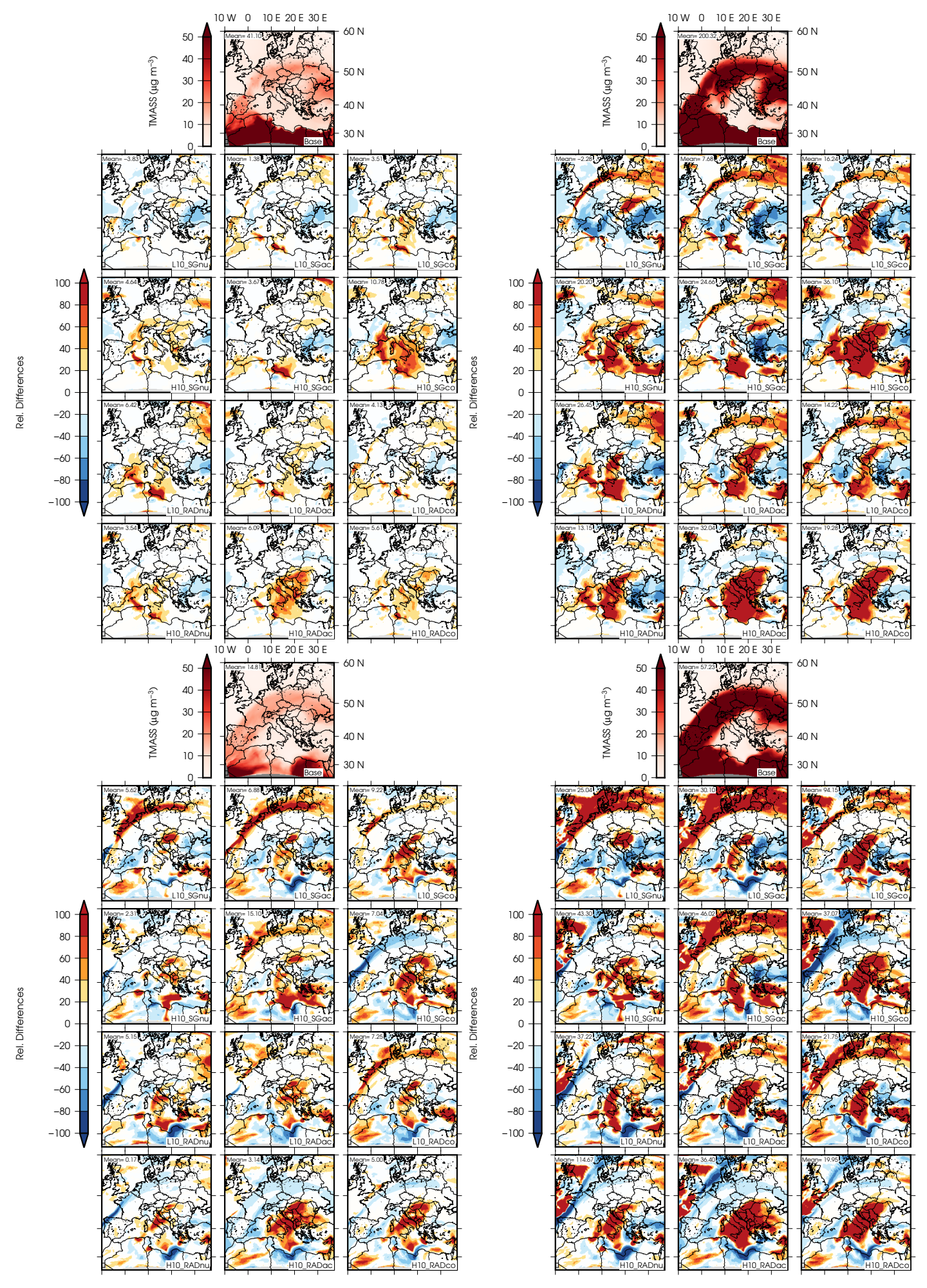

Figure 14. Id. Figure 12 but for sensitivity test at $10 \%$. 

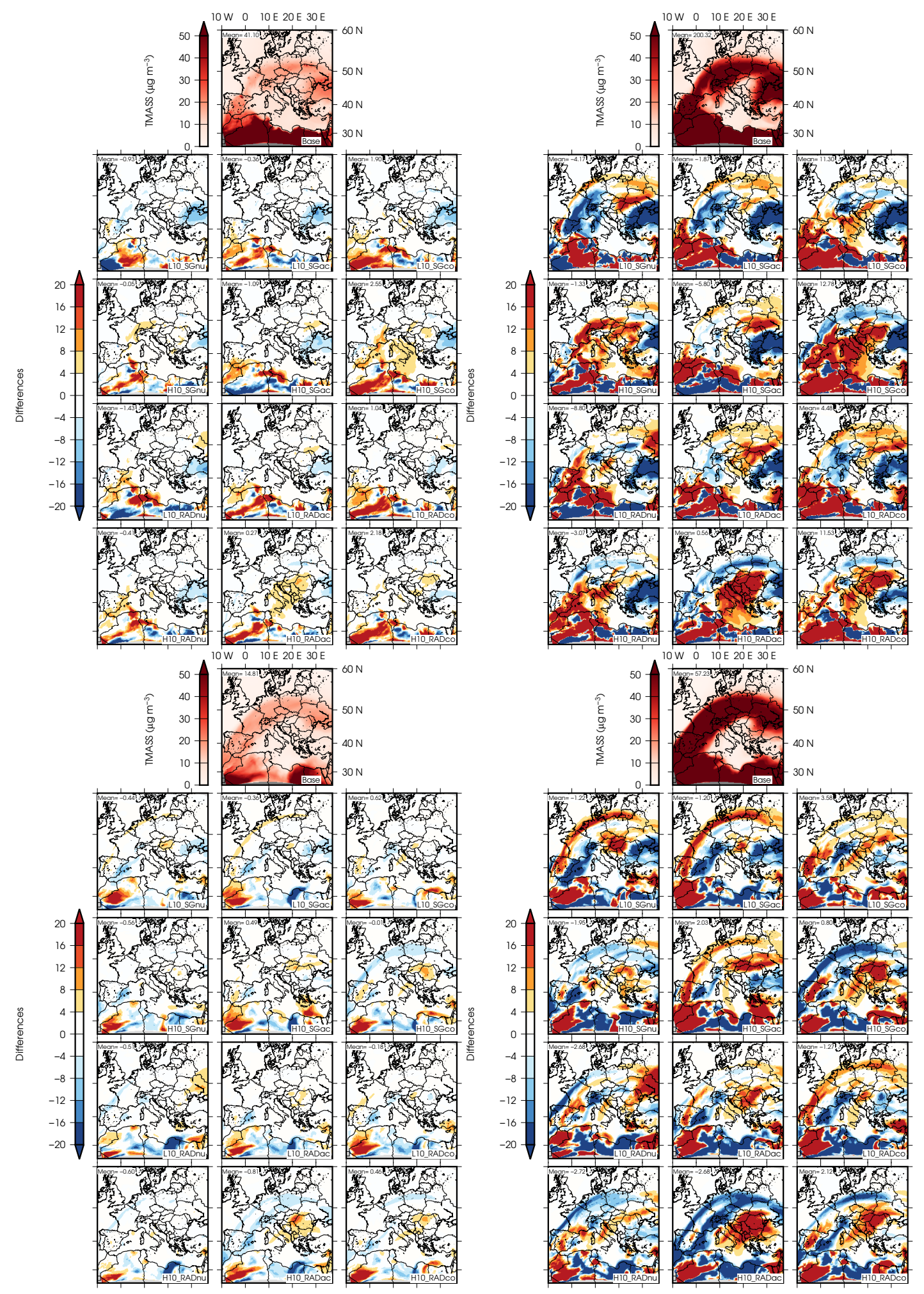

Figure 15. Id. Figure 11 but for sensitivity test at $10 \%$. 


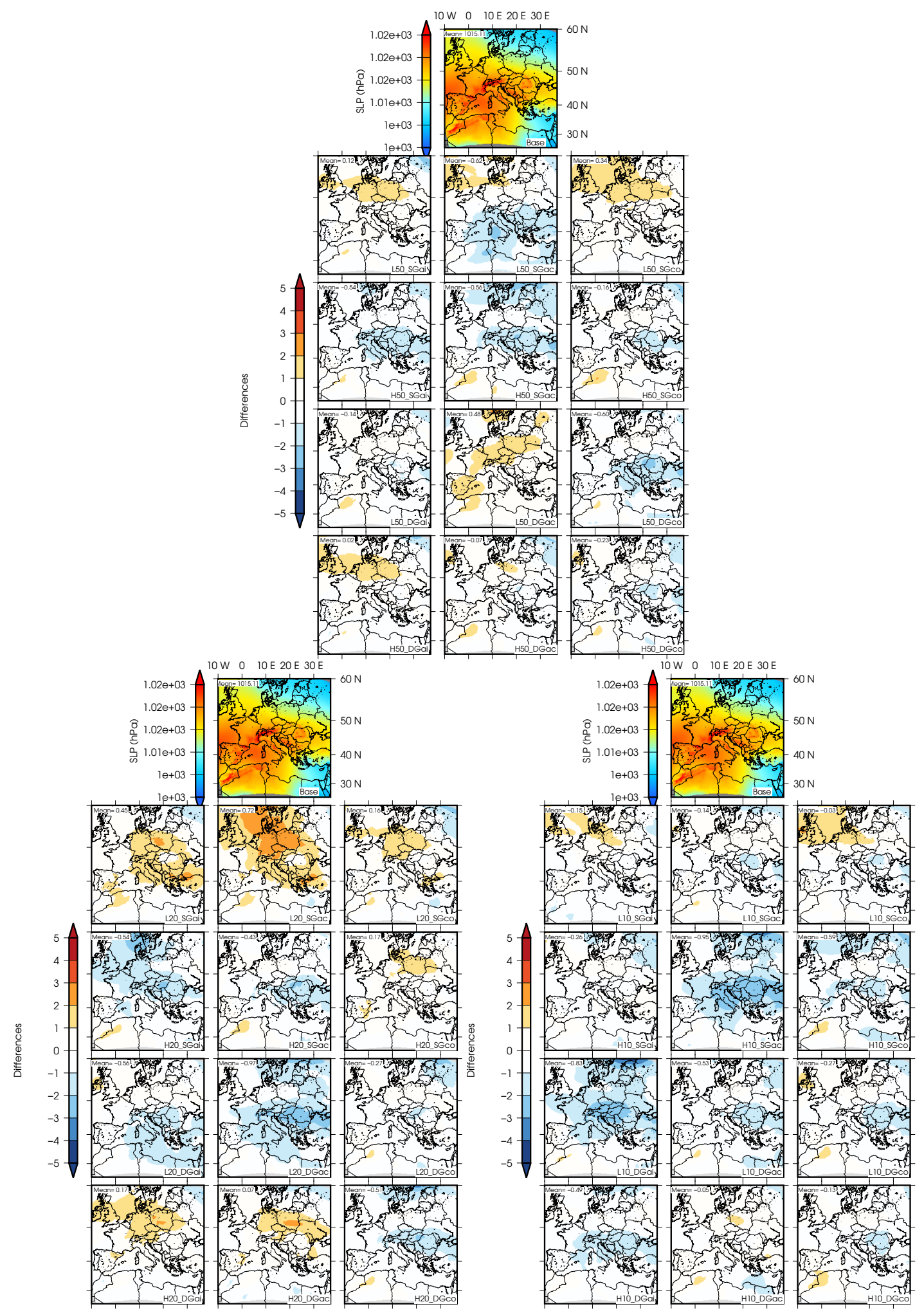

Figure 16. SLP for the base case and its variations for sensitivity test sjmulations at 50 (top), 20 (bottom-left) and $10 \%$ (bottom-right). 